\title{
The Effective Adsorption of Phosphate and Nitrate Using Spent Coffee Ground Loaded Iron and the Effect for Plant Growth
}

\author{
Aisyah Humayro $^{1}$, Hiroyuki Harada ${ }^{1 *}$, Kanako Naito ${ }^{1}$, Atsushi Hashimoto ${ }^{1}$ \\ ${ }^{I}$ Department Environmental Science, Prefectural University of Hiroshima, Shobara, 727-0023, Japan* \\ Corresponding author. Email: ho-harada@pu-hiroshima.ac.jp
}

\begin{abstract}
The aim of this study is to determine the effectiveness of phosphate and nitrate adsorption through several parameters, such as different initial concentrations, kinetic behaviour, the effect of $\mathrm{pH}$, and ratio liquid solid. $\mathrm{Fe}$ SCG showed the adsorption capacity values were $35.82 \mathrm{mg} / \mathrm{g}$ for phosphate and $20.5 \mathrm{mg} / \mathrm{g}$ for nitrate, respectively. Adsorption rate was observed rapidly in the first 60 minutes for phosphate and 90 minutes for nitrate by Fe-SCG. The kinetic experiment showed that the fitting of the pseudo-second order model was more satisfactory with coefficient correlation were 0.9586 for phosphate and 0.9783 for nitrate. The experimental data of both adsorptions were fitted well to Freundlich isotherm. The optimum $\mathrm{pH}$ of adsorption phosphate and nitrate by Fe-SCG were reached $\mathrm{pH} 5$ and 7. In the adsorption process using Fe-SCG, iron ion had affinity to phosphate ion and become ferric phosphate. The value of phosphate adsorbed by Fe-SCG was $65.37 \mathrm{mg} / \mathrm{g}$ and nitrate were $35 \mathrm{mg} / \mathrm{g}$ in ratio liquid solid of $0.2 \mathrm{~g} / \mathrm{L}$. The germination index test values of the Fe-SCG showed values above 80, indicating that they did not have a toxic effect on plant growth. The effect of application for plant growth showed that Fe-SCG in $0.2 \%$ dose yielded the highest plant height compared to the other two doses.
\end{abstract}

Keywords: Adsorption, SCG, Iron, Phosphate, Nitrate.

\section{INTRODUCTION}

The human population has increased and has an impact on the need for food consumption. In supplying for consumption of the human population, there has been an increase in productivity in the industrial and agricultural sectors. The increase in productivity from the agricultural sector is directly proportional to the use of fertilizers in the agricultural field. The fertilizers used will then be absorbed by the soil, some are used for plant growth, but some are released following the flow of water and then accumulate as agricultural waste which contains excess nutrients. Wastewater which contains a lot of nutrients is not only produced from the agricultural sector, but also from industrialization, livestock waste, and household by various human activities [1].

Wastewater containing a high concentration of nutrients such as phosphate and nitrate is a serious concern in the environment worldwide because both are implicated in the eutrophication of receiving water [2]. The eutrophication will deteriorate the water quality in terms of high turbidity, low dissolved oxygen concentration, unpleasant odor, and bad flavor. Furthermore, the presence of ion nitrate in drinking water is a potential public health hazard. A high concentration of nitrate leads to the production of nitrosamine, which is related to cancer [3]. On the other hand, phosphorus in the form of phosphate and nitrogen in the form of nitrate is an important part of the mechanism of plant growth in the agricultural sector.

Several physical-chemical and biological methods are developed to manage phosphate and nitrate in wastewater. The chemical precipitation, crystallization processes, adsorption, and biological methods are extensively studied during past decades. Adsorption is one in all the techniques for removal anions from aqueous solution, which is relatively more useful and low cost using easily available materials in wastewater treatment has been widely investigated, including in removal phosphate and nitrate cases. [4]. Several researchers used conventional adsorbents like 
activated carbon and alumina, the application of lowcost and simply available material in wastewater treatment has been studied in recent years.

Coffee is one of the foremost popular drinks worldwide, with a big quantity of by-products likewise about $6 \mathrm{Mt} / \mathrm{ye}$. Consequently, the coffee industry is accountable for producing large amounts of coffee residues. One of the residues is Spent Coffee Ground (SCG) [5]. SCG is one of the biomasses that is suitable to be used as an adsorbent because it has porous characteristics on its surface. Therefore, SCG is commonly used as an adsorbent for the removal of heavy metals or dyes [6] [7]. Supported the previous research, the adsorption of phosphate and nitrate using original SCG showed a low adsorption capacity. A good method is necessary to increase the adsorption capacity of this raw material. Some researchers mentioned one technique is to make biochar and activate the biochar adsorbent surface with an acid, such as hydrochloric acid. Another method is using metal hydroxides, such as iron hydroxide [8] [9]. Iron has a high affinity against oxyanion, such as arsenate and phosphate, and are selective in the adsorption process. The mechanism for phosphate removal is adsorb onto iron surface and formation of ferric phosphate [8].

\section{EXPERIMENTAL CONDITION}

\subsection{Preparation of Adsorbent}

The samples of SCG in this study was collected from a coffee machine at a convenience store in Shobara City, Hiroshima, Japan. First, SCG was washed using distilled water and dried in the oven for 1 - 2 days at $60^{\circ} \mathrm{C}$. After, it was sifted using a test sieve by Tokyo Screen Co., Ltd. with a sieving size of 425 $\mu \mathrm{m}$. The pure SCG was immersed in $0.1 \mathrm{M}$ ferric chloride with a ratio of $5 \mathrm{~g}$ of pure SCG in $200 \mathrm{~mL}$ ferric chloride solution for 24 hours, after that filtered and dried in an oven at $60^{\circ} \mathrm{C}$. The product is treated with iron called Fe-SCG.

\subsection{Adsorption Study}

Evaluation of adsorption characteristic phosphate and nitrate in this study was conducted using a batch experiment. Stock solution of phosphate and nitrate (having a concentration of $2000 \mathrm{mg} / \mathrm{L}$ ) was prepared by dissolving nitric acid and phosphoric acid in distilled water. Some various concentrations (10-500 $\mathrm{mg} / \mathrm{L})$ were prepared from which working solution. Furthermore, the adsorbent was immersed in phosphate and nitrate solution. The mixture was subsequently placed in a water bath shaker for the adsorption process to begin. A kinetic adsorption experiment was conducted in several time ranges until reaching the equilibrium condition. The effect of initial concentration from $\mathrm{pH}$ range $1-9$ by $1 \mathrm{M}$ hydrochloric acid and $1 \mathrm{M}$ potassium hydroxide solution. In the liquid-solid ratio experiment, various liquid-solid ratio $(0.02,0.1$, and $0.2 \mathrm{~L} / \mathrm{g})$ were used for phosphate and nitrate adsorption at a fixed time (depend on the kinetic experiment), the volume of the solution is not changed but the weight of the adsorbent is varied. Adsorption capacity $(q)$ was determined using the following equation:

$q=\frac{C_{0}-C e}{m} x V$

where $q(\mathrm{mg} / \mathrm{g})$ represents the adsorption capacity, $\mathrm{Ce}$ and $\mathrm{Co}(\mathrm{mg} / \mathrm{L})$ show for equilibrium and initial concentrations, respectively, $V(\mathrm{~L})$ is the volume of the solution, and $m(\mathrm{~g})$ is the mass of adsorbent.

\subsection{Adsorption Study}

The acute toxicity of Fe-SCG was determined based on a plant germination test. First, each of the FeSCG $(0.1 \%, 0.2 \%$, and $0.3 \%)$ was mixed with distilled water in a ratio of 1:10, thus placed in a shaker for 1 hour. The aim was to release the nutrients in the enriched SCGs. Further, separated liquid and solid using qualitative filter paper. After that, 10 seeds of Raphanus sativus were spread in a petri-dish that has been given a substrate. Then, $10 \mathrm{~mL}$ of the Fe-SCG extract was added to the substrate as a source of nutrition for the seeds. The petri-dish incubated in the dark at room temperature for 72 hours [10]. Percentage of seed germination $(S G \%)$ and germination index $(G I)$ were calculated using this following formula:

$$
\begin{aligned}
& S G(\%)=\frac{S G \% \text { in sample }}{S G \% \text { in control }} \times 100 \\
& G I=\frac{S G \% \text { in sample }+ \text { root length in sample }}{S G \% \text { in control }+ \text { root length in control }} \times 100
\end{aligned}
$$

\subsection{The Effect for Plant Growth}

In this part, to determine the effect of Fe-SCG fertilizer on the growth of white radish (Raphanus sativus), a pot experiment was conducted. Further, mini polybags with a diameter of $8 \mathrm{~cm}$ were filled with $150 \mathrm{~g}$ of soil as a medium. The soil used came from the field centre of the Prefectural University of Hiroshima, Shobara city. The soil type is sandy loam. The effect of adding fertilizer was monitored using a concentration ratio of $0 \%$ (without adding fertilizer, as 
a control), $0.1 \%, 0.2 \%$, and $0.3 \%$ for Fe-SCG. Each pot contains 8 seeds of Raphanus sativus. This pot experiment was carried out in a mini greenhouse which was controlled for temperature and humidity. The vegetative growth of plants was observed for 10 days. Parameters observed were plant height, leaf width, and root length (after 10 days). Each treatment was repeated 2 times.

\subsection{Analytical Methods}

The phosphate and nitrate adsorption performances were compared by a decrease of phosphate and nitrate amount in the solution were determined by the Japan Industrial Standard K 0102 (46.1.1 with molybdenum blue visual colorimetric method and 43.2.3 with naphthylethylenediamine visual colorimetric method). A portable $\mathrm{pH}$ meter (Horiba) was used to determine the $\mathrm{pH}$ value in the effect of the $\mathrm{pH}$ experiment. The morphology characteristic of the adsorbent was analyzed with a scanning electron microscope (SEM) (HITACHI TM3000). Surface area, total pore volume, and porosity were analyzed with Shimadzu TechnoResearch Incorporation. The functional groups on the surface were analyzed using Attenuated Total Reflection-Fourier Transform Infra-Red (FTIR-ATR). All chemicals were either reagent on analytical grade and purchased from Kanto Chemical Co. Inc. and Wako pure chemical corporation.

\section{RESULTS AND DISCUSSION}

\subsection{Characteristics of Fe-SCG}

Figures 1 and 2 show the SEM images of the original and Fe-SCG. SEM was used to observe the morphology of the adsorbent. Treatment using iron did not increase the surface area or porosity of SCG. However, the addition of iron gives an advantage to SCG for adsorbing more phosphate and nitrate. FTIR was used to analyze the functional groups on the adsorbent before and after modification. The spectra are shown in Figure 3, that original SCG had a strong broad absorption band at $3331 \mathrm{~cm}^{-1}$ is due to stretching of the hydroxyl functional groups referring to carboxylic acids; similar absorption bands also appear on Fe-SCG. The hydroxyl groups cause an increase in the electrostatic adsorption of anions, such as nitrate [11]. The two sharp bands at 2923 and $2852 \mathrm{~cm}^{-1}$ are attributed to $\mathrm{C}-\mathrm{H}$ stretching vibration. The original SCG has a peak between 1700 and $1600 \mathrm{~cm}^{-1}$ is highly associated with chlorogenic acids and caffeine [12].
However, Fe-SCG that peak has disappeared. The existence of caffeine content is very important because it has the potential to inhibit plant growth.

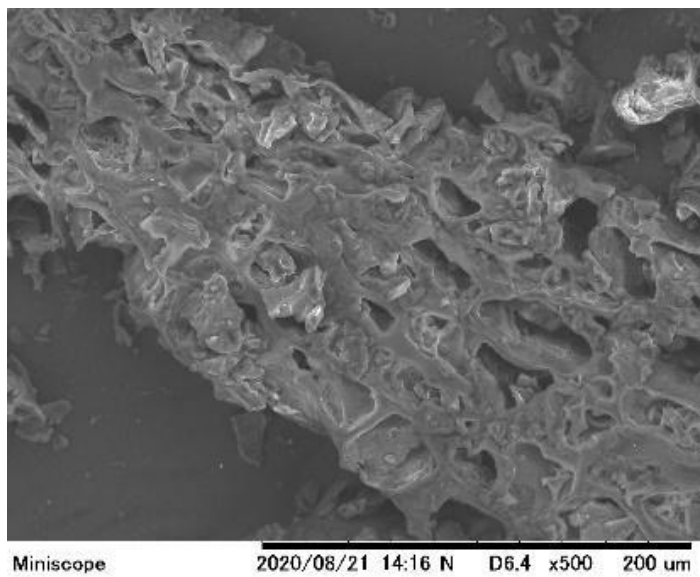

Figure 1 Scanning Electron Microscopy (SEM) images of original SCG

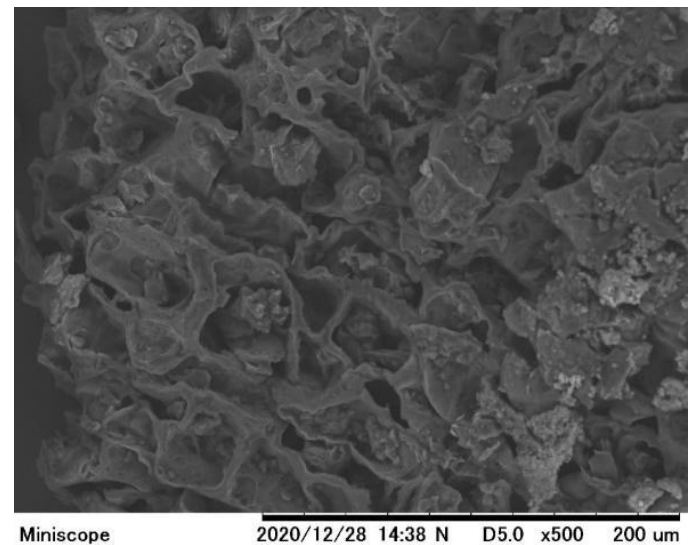

Figure2 Scanning Electron Microscopy (SEM) images of Fe-SCG

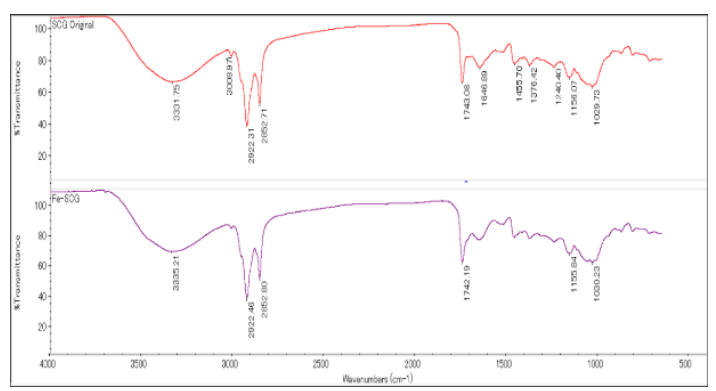

Figure 3 FTIR analysis of original and chemically modified SCG

\subsection{Adsorption Phosphate and Nitrate}

In preliminary research, it was found that the adsorption capacity of the original SCG (liquid/solid ratio of $0.01 \mathrm{~L} / \mathrm{g}$ ) showed low values, $1.86 \mathrm{mg} / \mathrm{g}$ for 
phosphate and $1.5 \mathrm{mg} / \mathrm{g}$ for nitrate, respectively. Based on Figure 4, the figure shows the adsorption capacity of original SCG and Fe-SCG. From that figure, the adsorption capacity of Fe-SCG showed a significant increase when compared to the original SCG (in previous research). Iron covering the surface of SCG pores play an important role in binding phosphate and nitrate ions. Fe-SCG showed the adsorption $35.82 \mathrm{mg} / \mathrm{g}$ for phosphate and $20.5 \mathrm{mg} / \mathrm{g}$ for nitrate, respectively.

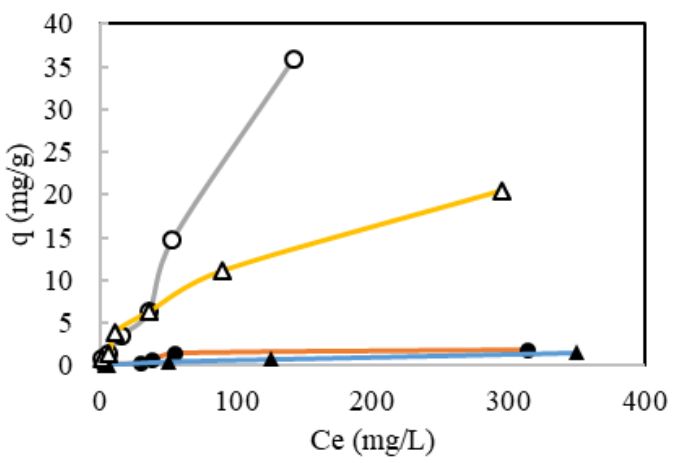

Figure 4 Phosphate and nitrate adsorption by original SCG and Fe-SCG from single solution (initial concentration: $10-500 \mathrm{mg} / \mathrm{L}, \mathrm{pH}$ solution : 3-4, ratio $\mathrm{L} / \mathrm{S}: 0.1 \mathrm{~L} / \mathrm{g}, 30^{\circ} \mathrm{C}, 100 \mathrm{rpm}, 24$ hours)

\subsection{Adsorption Kinetic}

The kinetic model is used to determine the adsorption rate, the performance of the adsorbent used, and the mass transfer mechanism. The adsorption mass transfer kinetic includes three steps, external diffusion, internal diffusion, and adsorption on active sites. Active sites mean that there is a part of an adsorbent that has been modified (by chemicals for example) which can bind to the adsorbed ion. To determine the appropriate kinetic model for the adsorption mechanism of phosphate and nitrate, it is necessary to describe the relationship between the concentration of phosphate and nitrate adsorbed and equilibrium time. In this study, the experimental data of both chemically modified SCG were simulated by pseudo-first order and pseudo-second order kinetic models, respectively. The kinetic models can be expressed as [13]:

$$
\begin{aligned}
& \ln \left(q_{e}-q_{t}\right)=\ln q_{e}-k_{1} t \\
& \frac{t}{q_{t}}=\frac{1}{k_{2} q_{e}{ }^{2}}+\frac{t}{q_{e}}
\end{aligned}
$$

where $\mathrm{k} \_1$ ( $\mathrm{g} /(\mathrm{mg}$.minute $\left.)\right)$ is the pseudo-first order rate constant, $\mathrm{k} \_2$ (g/(mg.minute) ) is the pseudosecond order rate constant, qe $(\mathrm{mg} / \mathrm{g})$ is the adsorption capacity at equilibrium, and $\mathrm{qt}(\mathrm{mg} / \mathrm{g})$ is the adsorption capacity at $\mathrm{t}$ (minute).

Kinetic studies of adsorption phosphate and nitrate onto Fe-SCG were conducted at various times. Figures 5 show thes equilibrium time of adsorption by $\mathrm{Fe}$ SCG. As shown in those figures, rapid adsorption was observed in the first 60 minutes for phosphate and 90 minutes for nitrate by $\mathrm{Fe}-\mathrm{SCG}$. The kinetic parameters of all experimental data listed in Table 1 showed the fitting of the pseudo-second order model was more satisfactory with coefficient correlation $\geq 0.9$, which indicated that the modified adsorbents are abundant with active sites.

Table 1 Pseudo-second order for phosphate and nitrate adsorption on Fe-SCG

\begin{tabular}{lllr}
\hline & Parameter 1 & Parameter 2 & $\mathbf{R}^{\mathbf{2}}$ \\
\hline & $\mathrm{K}_{2}=0.00347$ & & \\
& $\mathrm{~g} /(\mathrm{mg}$. minute & $\mathrm{q}_{\mathrm{e}}=16.23$ & 0.958 \\
$\mathrm{PO}_{4}$ & ) & $\mathrm{mg} / \mathrm{g}$ & 6 \\
& $\mathrm{~K}_{2}=0.00542$ & & \\
$\mathrm{NO}$ & $\mathrm{g} /(\mathrm{mg}$. minute & $\mathrm{q}_{\mathrm{e}}=21.83$ & 0.978 \\
3 & ) & $\mathrm{mg} / \mathrm{g}$ & 3 \\
\hline
\end{tabular}

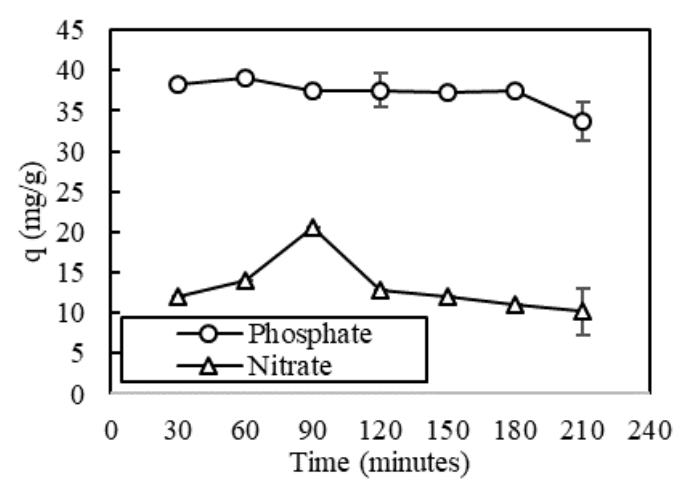

Figure 5 Equilibrium time of phosphate and nitrate adsorption by Fe-SCG (initial concentration: 500 $\mathrm{mg} / \mathrm{L}$, pH solution : $3-4$, ratio $\mathrm{L} / \mathrm{S}: 0.1 \mathrm{~L} / \mathrm{g}, 30^{\circ} \mathrm{C}, 100$ $\mathrm{rpm})$

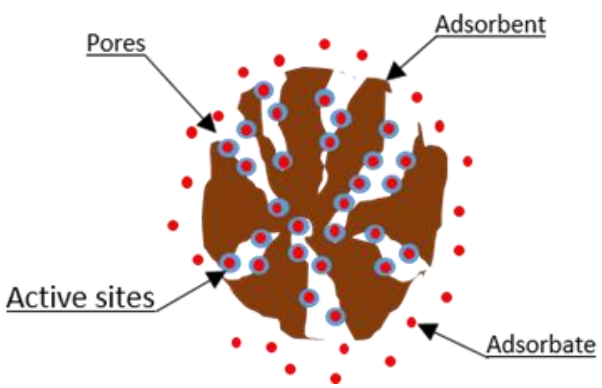

Figure 6. Illustration of adsorption on active sites. 


\subsection{Adsorption Isotherm}

Adsorption isotherm describes the equilibrium performance of adsorbents when the temperature is constant. The adsorption isotherm model provides information about the capacity of the adsorbent and solute-sorbent interaction, and the foremost important process properly is that the adsorption equilibrium. Within this work, the Langmuir and Freundlich isotherm was accustomed to analyze the experimental equilibrium data. Generally, adsorption is described as physisorption and chemisorption. Physisorption occurs due to the weak electrostatic interaction, while chemisorption happens when chemical bond forms between the adsorbate and the substrate by either sharing or transferring electrons. The chemisorption interaction is 2 orders stronger than the physisorption interaction [14].

The Langmuir model is indicating that there is monolayer coverage of adsorbate on a homogeneous adsorbent surface. The Langmuir isotherm described in the following equation [14]:

$$
\frac{C_{e}}{q_{e}}=\frac{1}{K_{L} q_{m}}+\frac{C_{e}}{q_{m}}
$$

Where $q_{m}(\mathrm{mg} / \mathrm{g})$ is the maximum of the adsorption capacity in monolayer condition, $q_{e}(\mathrm{mg} / \mathrm{g})$ is equilibrium capacity, $K_{L}(\mathrm{~L} / \mathrm{mg})$ and $C_{e}(\mathrm{mg} / \mathrm{L})$ is equilibrium concentration. While the Freundlich isotherm model is based on assumption that the heterogeneity of the adsorbent material and multilayer coverage of the adsorbate. The Freundlich isotherm equation is [14]:

$$
\log \log q=\log \log K_{f}+\frac{1}{n} \log \log C_{e}(7)
$$

where $K_{f}$ is the Freundlich isotherm, $n$ is the adsorption intensity, $C_{e}(\mathrm{mg} / \mathrm{L})$ is the equilibrium concentration, $q_{e}(\mathrm{mg} / \mathrm{g})$ is the equilibrium capacity.

Table 2 Adsorption isotherm models for phosphate and nitrate on different chemically modified SCG

\begin{tabular}{lccc}
\hline & Parameter 1 & Parameter 2 & $\mathbf{R}^{\mathbf{2}}$ \\
\hline $\mathrm{PO}_{4}$ & $\mathrm{~K}_{\mathrm{F}}=0.3661$ & $\mathrm{n}=1.13$ & 0.9679 \\
$\mathrm{NO}_{3}$ & $\mathrm{~K}_{\mathrm{F}}=0.6122$ & $\mathrm{n}=1.57$ & 0.9596 \\
\hline
\end{tabular}

The adsorption isotherm of phosphate and nitrate ions on Fe-SCG is shown in Table 2. The experimental data of Fe-SCG was fitted well to Freundlich isotherm $\left(\mathrm{R}^{2}>0.9\right)$, indicating the surface of the adsorbent was heterogeneous and multi-layer coverage of the adsorbents. Besides, when $1 / \mathrm{n}$ is greater than zero $(0<$ $1 / \mathrm{n}<1$ ) indicates favourable adsorption [15]. The Freundlich isotherm equation model is quite difficult to determine the optimum value of the adsorption or its equilibrium conditions because the adsorption capacity will increase as the initial concentration of the solution increases. The addition of ferric was played important role in adsorption phosphate and nitrate, which is indicating not only physical adsorption but also chemical adsorption.
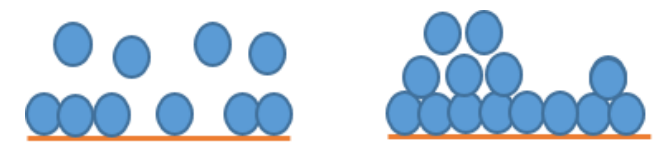

Figure 7 Illustration of adsorption models, (a) Langmuir and (b) Freundlich

\subsection{Effect of pH on Phosphate and Nitrate Adsorption}

The $\mathrm{pH}$ of the solution is an important point in the adsorption process because it affects the surface charge of the adsorbent and the chemical speciation of the adsorbate. In this study, a range of $\mathrm{pH}$ (1-9) was studied to know the effect of $\mathrm{pH}$ on phosphate and nitrate removal from an aqueous solution. The optimum $\mathrm{pH}$ of adsorption phosphate and nitrate by Fe-SCG were reached $\mathrm{pH} 5$ and 7. Thus, the lower the $\mathrm{pH}$ of the solution will provide an advantage in the adsorption process. The chemically modified SCG surface would be positively charged when the solution $\mathrm{pH}$ was lower, which enhanced the adsorption possibility for the negatively charged phosphate and nitrate ions [15].

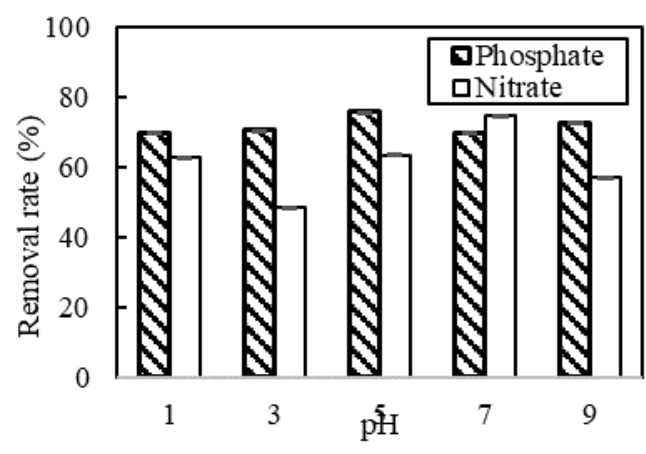

Figure 8. The removal rate of phosphate and nitrate by Fe-SCG at different $\mathrm{pH}$ (initial concentration: 500 $\left.\mathrm{mg} / \mathrm{L}, 30^{\circ} \mathrm{C}, 100 \mathrm{rpm}\right)$ 


\subsection{Adsorption Mechanism of Phosphate and Nitrate}

SCG has a hydroxyl group functional group having a high affinity for the nitrate ion. The $\mathrm{pH}$ of the solution also affects the formation of phosphate produced. Theoretically, when the $\mathrm{pH}$ of the solution is under 2.15, the dominant form of phosphate produced is $\mathrm{H}_{3} \mathrm{PO}_{4}$, and when $\mathrm{pH}$ ranges from 2.15-7 the dominant form is $\mathrm{H}_{2} \mathrm{PO}_{4}$. $\mathrm{HPO}_{4}$ is more dominant at $\mathrm{pH}$ 7.20-12.33 [9]. So $\mathrm{H}_{2} \mathrm{PO}_{4}$ is the main ion to attract the adsorption site on chemically modified SCG. In the adsorption process using Fe-SCG, akaganeite was formed in the ferric chloride solution because of the interaction between chloride ions with the surface of the hydrous ion [8]. Moreover, ferric ion has high affinity with phosphate ion to become ferric phosphate.

\subsection{Liquid-Solid Ratio}

The effect of liquid-solid ratio is needed for knowing the best composition on phosphate and nitrate adsorption processes. Besides, by knowing the best composition, it will be known that the highest adsorption capacity of each adsorbent that will be used for fertilizer contributes to plant growth. From Figure 9 , it was observed that the amount of phosphate and nitrate per unit weight of adsorbent decreased when the adsorbent dose increased. The highest adsorption capacity is at a ratio of $0.2 \mathrm{~L} / \mathrm{g}$ with an adsorbent weight of $0.1 \mathrm{~g}$. In this ratio, the value of phosphate adsorbed by Fe-SCG was $65.37 \mathrm{mg} / \mathrm{g}$ and nitrate was $35 \mathrm{mg} / \mathrm{g}$. This shows that at a low adsorbent dose, the entire surface of the active site adsorbs more phosphate and nitrate ions. At a higher number of adsorbent doses, the removal rate is higher, but the more active site of the adsorbent is not filled with phosphate and nitrate ions because the adsorption capacity of the adsorbent is low. The liquid-solid ratio with the highest adsorption capacity value will later be used to contribute to the plant growth experiment.

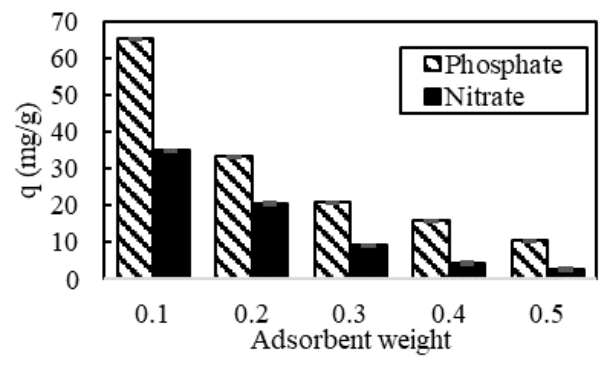

Figure 9. The effect of different liquid-solid ratio on adsorption capacity of Fe-SCG (initial concentration: $\left.500 \mathrm{mg} / \mathrm{L}, 30^{\circ} \mathrm{C}, 100 \mathrm{rpm}\right)$

\subsection{Acute Toxicity}

Caffeine content in SCG of $1.68 \mathrm{mg} / \mathrm{g}$ has been investigated. Caffeine present in SCG can inhibit plant growth because of toxicity potential [16]. One method that can be used to measure the level of toxicity is the germination index method. Seed germination index (GI) was defined as a factor of relative seed germination and relative root elongation [17]. The original SGC had a GI value of 83 , whereas after the enrichment process the GI value increased by more than 90. A germination index value of more than 80 indicates that the fertilizer does not have a toxic effect on plant growth [18]. A higher germination index indicating that well matured and stabilized compost [17]. In addition, analysis of the characteristics enriched SCGs using FTIR, the peak indicating caffeine disappeared and was replaced with another functional group.

Table 3 Germination index

\begin{tabular}{cc}
\hline Composition of fertilizer & Fe-SCG \\
\hline $0.10 \%$ & 192 \\
$0.20 \%$ & 123 \\
$0.30 \%$ & 100 \\
\hline
\end{tabular}

\subsection{The Effect for Plant Growth}

The effect of Fe-SCG for contributing for plant growth (Raphanus sativus) can be seen in Figure 10. After 10 days of observation, all concentration ratios of the Fe-SCG were able to give a good effect on the growth of Raphanus sativus plants when compared to the control. Simultaneously, the ratios of $0.1 \%, 0.2 \%$, and $0.3 \%$ of Fe-SCG fertilizer began to grow on the third day. Moreover, plant growth with $0.2 \%$ ratio treatment grew the fastest than others.

Table 4 Characteristic of original SCG and after enrichment process

\begin{tabular}{lcc}
\hline & Original SCG & Fe-SCG \\
\hline $\mathrm{pH}$ & 4.89 & 4.30 \\
$\mathrm{Ca}^{2+}(\mathrm{mg} / \mathrm{g})$ & 0.46 & 0.97 \\
$\mathrm{Mg}^{2+}(\mathrm{mg} / \mathrm{g})$ & 0.73 & 0.98 \\
$\mathrm{PO}^{3-}(\mathrm{mg} / \mathrm{g})$ & 3.45 & 65.4 \\
$\mathrm{NO}_{3}{ }^{-}(\mathrm{mg} / \mathrm{g})$ & 3.1 & 35 \\
$\mathrm{~K}^{+}(\mathrm{mg} / \mathrm{g})$ & 1.52 & 0.04 \\
$\mathrm{Fe}^{3+}(\mathrm{mg} / \mathrm{g})$ & 0.17 & 2.51 \\
\hline
\end{tabular}



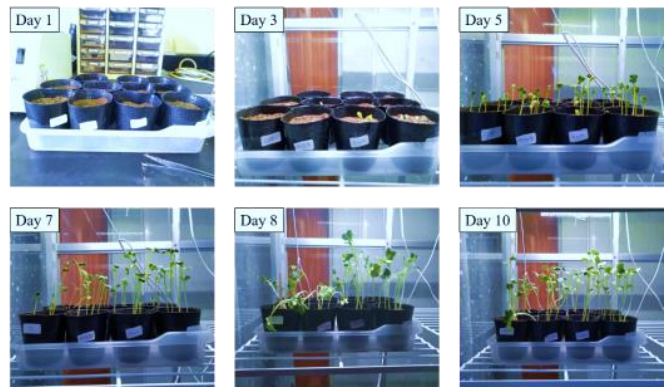

Figure 10 The application of Fe-SCG fertilizer on

pot treatment experiment

Figure 11 shows details regarding the increase in plant height day by day for 10 days. The effect in application of Fe-SCG fertilizer, the plant height from the $0.2 \%$ dose was higher than the other doses. The presence of additional nutrients in SCG is a strong reason for the increase in height of Raphanus sativus plants. Plants are sufficiently supplied with nitrogen can stimulate plant in vegetative growth, including increasing plant height. Sufficient nitrogen content in plants also makes plants greener [19].

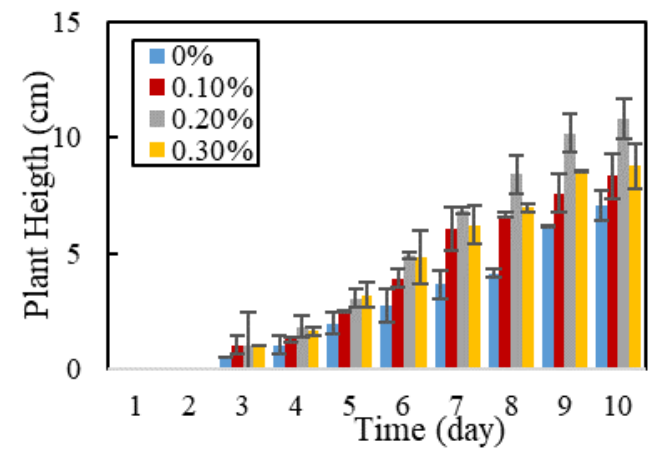

Figure 11 The effect of Fe-SCG fertilizer on plant height of Raphanus sativus

Figure 12 shows the development of leaf width of the Raphanus sativus plant. In the application of FeSCG fertilizer, the development of leaf width was better. The presence of iron is quite important in this case (Table 4). Iron plays a role in plant respiration and the formation of leaf green matter (chlorophyll) [20].

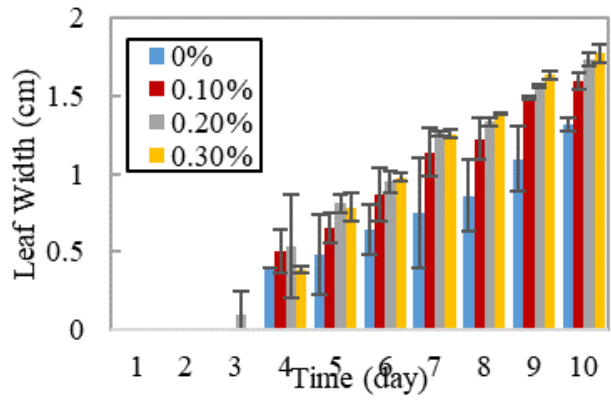

Figure 12 The effect of Fe-SCG fertilizer on leaf width of Raphanus sativus

\section{CONCLUSION}

In this study, it has been proven that the development of SCG as an adsorbent to remove phosphate and nitrate by modifying it using iron has a higher adsorption capacity than without any treatment. The Fe-SCG showed the adsorption capacity values were $35.82 \mathrm{mg} / \mathrm{g}$ for phosphate and $20.5 \mathrm{mg} / \mathrm{g}$ for nitrate, respectively. The kinetic studies suggested that the adsorption process might be suitable with pseudosecond order. $\mathrm{pH}$ had an important role in the mechanism of phosphate and nitrate adsorption because it affected the surface charge of the SCG porous. From this study obtained phosphate fertilizer product, ferric phosphate. The application of fertilizer from Fe-SCG gives a good impact on the growth of white radish plants (Raphanus sativus) when compared with without treatment, in increasing plant height and developing leaf width. The germination index test values showed value above 80 , indicating that they did not have a toxic effect on plant growth. The conclusion is that Fe-SCG has potential as alternative fertilizers in the future, of course with the accompanying development technology.

\section{REFERENCES}

[1]. Chitrakar, R., Tezuka, S., Sonoda, A., Sakane, K., Ooi, K., and Hirotsu, T. (2006). Phosphate Adsorption on Synthetic Goethite and Akagenite. Journal of Colloid and Interface Science, 298, 602-608.

https://doi.org/10.1016/j.jcis.2005.12.054.

[2]. Jorgensen, S.E., and Williams, W.D. (2001). Water Quality: The Impact of Eutrophication. Volume 3. International Environmental Technology Centre, Osaka. 
[3]. Kioussis, D.R., Wheaton, F.W. and Kofinas, P. (2000). Reactive Nitrogen and Phosphorus Removal Aquaculture Wastewater Effluents Using Polymer Hydrogels. Aquaculture Engineering, 23, 315-332.

https://doi.org/10.1016/S0144-8609(00)00058$\underline{3}$.

[4]. Yin, Q., Zhang, B., Wang, R., and Zhao, Z. (2017). Biochar as an Adsorbent for Inorganic Nitrogen and Phosphorus Removal from Water: A review. Environmental Science and Pollution Research, 24, 26297-26309. https://doi.org/10.1007/s11356-017-0338-y.

[5]. Campos-Vega, R., Guadalupe Loarca-Pina, G., Vergara-Castenada, H.A., Oomah, B.D. (2015). Spent Coffee Grounds a Review on Current Research and Future Prospects. Trends in Food Science and Technology, 45, 24-36. https://doi.org/10.1016/j.tifs.2015.04.012.

[6]. Anastopoulos, I., Karamesouti, M., Mitropoulos, A., Kyzas, G. (2017). A Review for Coffee Adsorbents. Journal of Molecular Liquid, 229, 555-565. https://doi.org/10.1016/j.molliq.2016.12.096.

[7]. Fiol, N., Escudero, C. and Villaescusa, I. (2008). Re-Use of Exhausted Ground Coffee Waste for Cr (VI) Sorption. Separation Science and Technology, 43, 582-596. https://doi.org/10.1080/01496390701812418.

[8]. Li, J., Lv, G., Bai, W., Liu, Q., Zhang, Y., Song, J. (2014). Modification and Use of Biochar from Wheat Straw (Triticum aestivum) for Nitrate and Phosphate Removal from Water. Desalination and Water Treatment, 1-13. https://dx.doi.org/10/1080/19443994.2014.994 104.

[9]. Yang, Q., Wang, X., Luo, We., Sun, J., Xu, Q., Chen, F., Zhao, J., Wang, S., Yao, F., Wang, D., Li, X., Zeng, G. (2018). Effectiveness and Mechanisms of Phosphate Adsorption on IronModified Biochars Derived from Waste Activated Sludge. Bioresource Technology, 247, 537-544.

https://dx.doi.org/10.1016/j.biortech.2017.09.1 36.

[10]. Molnarova, M., Smelkova, M., Fargasova, A. (2014). Assessment of the Suitability of
Phytotoxkit Plastic Vertical Containers Compared with Petri Dishes for Standard Seedling Growth Tests. Bulletin of Environmental Contamination and Toxicology. 92(4), 497-501. https://doi.org/10.1007/s00128-013-1186-1.

[11]. Bhatnagar, A. and Sillanpaa, M. (2011). A Review of Emerging Adsorbent for Nitrate Removal from Water. Chemical Engineering Journal, 168, 493-504. https://doi.org/10.1016/j.cej.2011.01.103.

[12]. Craig, A.P., Franca, A.S., and Oliviera, L.S. (2012). Evaluation of the Potential of FTIR and Chemometrics for Separation between Defective and Non-Defective Coffees. Food Chemistry, 132, 1368-1374.

https://doi.org/10.1016/j.foodchem.2011.11.12 1 .

[13]. Wang, J. and Guo, X. (2020). Adsorption Kinetic Models: Physical Meaning, Applications, and Solving Methods. Journal of Hazardous Material, 360, Article ID: 122156.

https://doi.org/10.1016/j.jhazmat.2020.122156.

[14]. Al-Ghouti, M.M., and Da'ana, D.A. (2020). Guidelines for The Use and Interpretation of Adsorption Isotherm Models: A review. Journal of Hazardous Materials, 393, Article ID: 122383 .

https://doi.org/10.1016/j.jhazmat.2020.122383.

[15]. Taleb, M.F.A., Mahmoud, G.A., Elsigeny, S.M., and Hegazy, E.A. (2008). Adsorption and Desorption of Phosphate and Nitrate Ions Using Quaternary (Polypropylene- g-N, Ndimethylamino Ethylmethacrylate) Graft Copolymer. Journal of Hazardous Materials, 159, 372-379.

https://doi.org/10.1016/j.jhazmat.2008.02.028.

[16]. Campos-Vega, R., Guadalupe Loarca-Pina, G., Vergara-Castenada, H.A., Oomah, B.D. (2015). Spent Coffee Grounds a Review on Current Research and Future Prospects. Trends in Food Science and Technology, 45, 24-36. https://doi.org/10.1016/j.tifs.2015.04.012.

[17]. Moharana, P.C. and Biswas, D.R. (2016). Assessment of Maturity Indices of Rock Phosphate Enriched Composts using Variable 
Crop Residues. Bioresources Technology. 222, $1-13$.

http://dx.doi.org/10.1016/j.biortech.2016.09.09 7.

[18]. Tiquia, S.M., Tam, N.F.Y., Hodgkiss, I.J. (1996). Effect of Composting on Phytotoxicity of Spent Pig-Manure Sawdust Litter. Environmental Pollution. 93(3), 249-265. https://doi.org/10.1016/S0269-7491(96)00052$\underline{8}$.

[19]. Leghari, S.J., Wahocho, N.A., Laghari, G.M., Laghari, A.H., Bhabhan, G.M., Talpur, K.H., Bhutto, T.A., Wahocho, S.A., Lashari, A.A. (2016). Role of Nitrogen for Plant Growth and Development: A Review. Advances in Environmental Biology. 10(9), 209-218.

[20]. Rout, G.R. and Sahoo, S. (2015). Role of Iron in Plant Growth and Metabolism. Review in Agricultural Science. 3, 124.https://doi.org/0.7831/ras.3.1. 